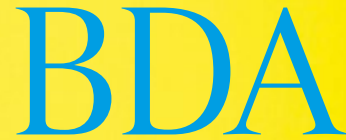

British Dental Association

\section{You deserve} the best support and advice

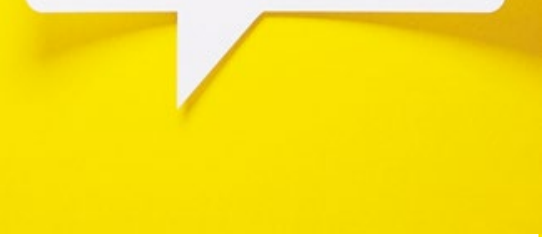

\section{Members can save time and money with personalised advice on:}

- Associateships and employment law

- The business of dentistry

- Compliance

- Employment relations and support

for salaried dentists

- Pensions

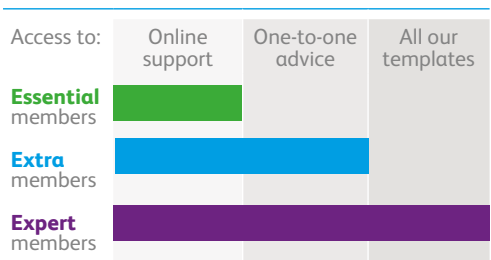

To upgrade call: 02075634550

Your questions answered bda.org/advice

$\star$ Trustpilot $\star \star \star|\star| \star \mid$

\title{
Dental tour all set to treat fishermen in Cornwall and Devon
}

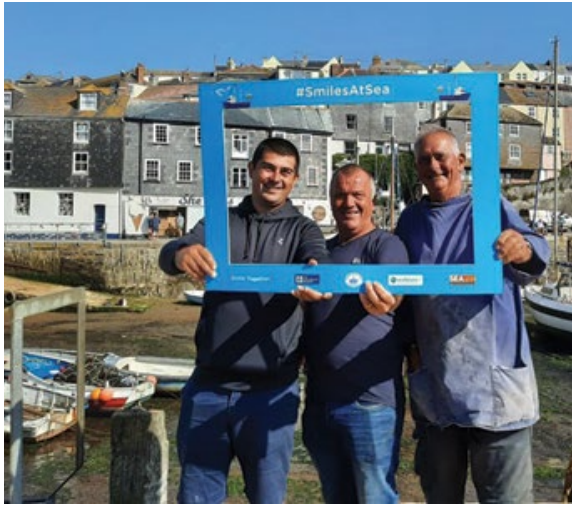

The SeaFit Programme is a joint initiative between two highly respected national maritime charities, the Fishermen's Mission and the Seafarers Hospital Society, with funding from Seafarers UK. SeaFit has partnered with Smile Together to provide this free dental advisory service to local fishermen and their families across Cornwall and Devon.

Covering Cornwall and the Isles of Scilly, Smile Together are one of the South West's largest NHS referral and emergency primary dental care providers. Their West Country Dental Care team provide urgent and emergency dental treatments for people who don't have their own dentist, run out-of-hours surgeries and apply expert skills to treat children and adults with a range of special care needs alongside oral surgery, children's orthodontics and treatments under general anaesthetic in a hospital setting

This year's \#SmilesAtSea and SeaFit tour of Cornwall and Devon will be a little different due to COVID-19 regulations. The initiative's focus will be on increasing fishermen and their families' knowledge and awareness of good oral health, along with reducing their sugar intake and changing their eating and toothbrushing habits to improve their dental health.

SeaFit Manager Carol Elliott said: 'We know how hard it can be to get to the dentist when you're out at sea and it's even more difficult at the moment, so we're bringing free dental advice and information to the harbourside instead. We've always been delighted with the response to this dental tour and many of the fishermen we've seen in the past hadn't seen a dentist for years, so knowing how to prevent the need for treatment is even more important now. We will be following local and national COVID-19 guidelines to keep people safe and there's no need to book - just turn up!'

Starting with Newquay on 16 September, the tour will visit five other fishing ports: Newlyn, Mevagissey, Padstow, Plymouth and Brixham throughout September and October.

\section{Dental visits can evoke traumatic memories}

A study by a Swedish endodontist has shown that the defencelessness experienced while sitting in the dentist's chair can prompt memories of sexual abuse.

Dr Eva Wolf interviewed 13 people, who had such experiences, and found many are scared and avoid going to the dentist, do not show up for scheduled appointments, or leave ongoing treatment.

According to Dr Wolf, the association with the abuse can lead to the patient shielding themselves from the experience, disappearing mentally and 'agreeing to anything' during the treatment, while on the surface they seem calm.

The study was conducted together with Gisela Priebe, an associate professor at the Department of Psychology at Lund University, and Erin McCarthy, a professor of philosophy at the University of St Lawrence, USA.

For the full story visit https://mau.se/ en/news/visits-to-the-dentist-can-evokememories-of-traumatic-sexual-abuse/. 